\title{
Más allá de Revuelta agraria. La huella antropohistórica y poética de Paul Friedrich en tierras p'urhépecha
}

\author{
Beyond the Agrarian Revolt. Paul Friedrich's anthropohistorical \\ and poetic imprint in P'urhépecha lands \\ Lorena Ojeda Dávila \\ UNIVERSIDAD MICHOACANA DE SAN NICOLÁS DE HIDALGO, lojeda@umich.mx
}

Este texto tiene como objetivo desempolvar el legado "antropohistórico", lingüístico y poético de Paul Friedrich, así como revalorar sus propuestas teórico-metodológicas multidisciplinarias en torno a sus estudios sobre los tarascos* de Michoacán.

PaLABRAS ClaVE: antropohistoria, etnopoesía, tarasco, p’urhépecha, cacicazgo.

The objective of this text is to dust off the "anthropohistorical", linguistic and poetic legacy of Paul Friedrich, and reevaluate his multidisciplinary theoretical-methodological proposals related to his studies of the Tarascans of Michoacán.

KEYwORDs: anthropohistory, ethnopoetics, Tarascans, P'urhépecha, cacicazgo.

Fecha de recepción del artículo: 23 de octubre de 2014 / Fecha de aprobación: 20 de abril de 2015 / Fecha de recepción de la versión final: 5 de junio de 2015

\section{A la memoria de Tata Pablo, con profundo respeto y agradecimiento}

l presente texto ${ }^{1}$ se fundamenta en siete entrevistas y varias
charlas informales de la autora con Paul Friedrich entre
2012 y 2014, en la revisión exhaustiva de las cuarenta y

*El gentilicio "tarascos" es la forma más usada para referirse a la historia de este pueblo indígena desde la época prehispánica hasta mediados de 1980, cuando movimientos de revitalización étnica pugnaron por el uso de "p'urhépecha". No se conoce con certeza el nombre que el pueblo se daba a sí mismo antes de la llegada de los españoles, ya que fueron éstos quienes los comenzaron a llamar generalizadamente "tarascos". En la actualidad la mayoría de sus miembros se autodenominan como p'urhépecha, siendo éste el término que prefiero emplear. Sin embargo, todos los textos de Friedrich se refieren a este grupo étnico y a su lengua como "tarascos", por lo cual en estas páginas respeto este nombre.

${ }^{1}$ Este trabajo fue posible gracias al apoyo para la reincorporación de becarios PROMEP 2012-2013, de la beca Fulbright-García Robles para investigadores mexicanos 
nueve cajas que contienen los documentos personales y de trabajo clasificados como "Paul Friedrich Papers" (Documentos de Paul Friedrich) en las Special Collections de la Universidad de Chicago, así como gran parte de la obra del autor sobre los tarascos. ${ }^{2}$

Estoy muy agradecido contigo porque despertaste mi imaginación. ¡ Has venido a hablar de cosas que sucedieron hace más de cincuenta ańos! Ahora tengo dificultad en dormir porque he estado pensando en todas esas cosas, y soñando... Es muy agradable recordarlas. ${ }^{3}$

Mi aprecio por el primer libro, Revuelta agraria, fue revivido recientemente cuando estaba muy enfermo y acababa de regresar del hospital. Siempre pensé que ese trabajo fue bueno en su momento pero que ya estaba en el cesto de basura de la historia, como casi todo lo demás. Pero entonces una joven historiadora mexicana llamada Lorena Ojeda Dávila vino a verme... y me dijo "Valoramos mucho sus libros, los estamos leyendo en Michoacán, los usamos en mi universidad". Eso me dio una tremenda motivación, el saber que mi primer libro no ha sido olvidado y está siendo leído. ${ }^{4}$

La metodología de la "antropohistoria”, la antropología lingüística y la etnopoesía propuestas por Paul Friedrich han ejercido influencia en muchas generaciones de especialistas en todo el mundo. Su trayectoria me permite caracterizarlo ante todo como un humanista cuyo pensamiento y obra evolucionaron constantemente durante

2013, así como de una beca para estancia posdoctoral del Conacyt llevada a cabo en la Universidad de California en Berkeley 2013-2015. Agradezco el apoyo de Mauricio Tenorio, Joshua Beck, James Fernandez, Anne Gamboa y Drew Dixon durante el proceso de investigación que permitió la elaboración de este texto, así como de John Attinasi, Paul Liffmann, Diego Iturralde, Andrew Roth y Anthony Wright por sus valiosos comentarios. Un especial agradecimiento a Domnica Radulescu por su generosidad.

${ }^{2}$ Todas las entrevistas fueron realizadas en inglés y han sido traducidas al español por la autora. De igual manera, la mayoría de los documentos contenidos en la colección Paul Friedrich Papers están en inglés y han sido traducidos al español por la autora.

${ }^{3}$ Paul Friedrich a la autora. Entrevista de la autora a Paul Friedrich, Chicago, 28 de junio de 2012.

${ }^{4}$ Paul Friedrich a Dale Pesmen. Paul Friedrich y Dale Pesmen, "A Conversation with Paul Friedrich", Annual Review of Anthropology, vol. 43 (2014): 15-26. La traducción del inglés es de la autora. 
más de medio siglo, a través de la exploración de distintos ámbitos del conocimiento y de la naturaleza humana, abarcando el estudio de la literatura, la historia y la filosofía, y continuaron con la antropología política, la antropología lingüística, hasta llegar a la etnopoesía, cada vez más recurrente en su obra a partir de la década de 1980. Sin embargo, hubo diversos periodos en los cuales Friedrich centró mayormente su atención al estudio de uno u otro campo o tema, siempre yendo y viniendo entre sus diferentes intereses académicos y pasiones personales. Si se leen con cuidado las obras de Friedrich, por muy diversas que parezcan las temáticas y enfoques que utilizó, se encuentran siempre las mismas preocupaciones científicas, los mismos pensamientos y las mismas pasiones que movieron al autor durante más de siete décadas de trabajo ininterrumpido.

En las siguientes páginas me centraré y presentaré las contribuciones de Paul Friedrich a partir de sus estudios sobre los tarascos, divididos en cinco apartados: Tata Pablo, un aristócrata con huaraches; La antropohistoria y otros trabajos sobre Michoacán; Friedrich y una "nueva etnografía”; El poeta etnógrafo y el etnógrafo poeta; $y$, finalmente, Friedrich: humanista global y "World Listener".

\section{Tata Pablo, un aristócrata con huaraches}

Nacido en 1927 en Cambridge, Massachusetts, Paul Friedrich tuvo una vida interesante e intensa, además de sumamente productiva en términos profesionales. Escribió más de veinte libros, decenas de artículos y capítulos de libro, sobre temas tan diversos como la antropohistoria, la etnopoesía, la antropología política, la indeterminación poética, el relativismo lingüístico, los árboles protoindoeuropeos, las aves en la Odisea, la cuestión homérica, la musicalidad en la poesía rusa, la poesía T’ang y Sung, la fonología de la lengua malayalam, el mito de Afrodita, los grandes escritores rusos, o la lengua y la política en la India, así como varios trabajos sobre la lengua, la política agraria y los cacicazgos tarascos, por mencionar sólo algunos. Impartió múltiples cursos en nueve universidades de gran prestigio. Hablaba inglés, ruso, alemán, tarasco, griego (ático, homérico y del Nuevo Testamento), sánscrito (de la Gita, clásico y védico), francés, latín, 
eslavo antiguo, italiano, serbio-croata, tagalo y hebreo y tradujo textos del ruso, griego, alemán, tarasco, español y malayalam.

Friedrich comenzó su vida académica estudiando lenguas, literatura comparada e historia intelectual en la Universidad de Harvard. Ahí fue reclutado por el famoso antropólogo Clyde Kluckhohn para el Centro de Investigación Ruso de Harvard, para realizar trabajo de campo (entrevistas principalmente) con minorías de refugiados rusos en Alemania durante ocho meses en 1949. Ése fue su primer contacto con la antropología y con los métodos etnográficos, mucho antes de comenzar a estudiarla formalmente. Esta experiencia en el campo influyó en su decisión de trasladarse a la Universidad de Yale para cursar un doctorado en antropología a principios de los ańos cincuenta. En 1955, llegó a Michoacán con apoyo de una beca Wenner-Gren y otra más del gobierno mexicano (Buenos Aires Convention Fellowship) para hacer trabajo de campo en un proyecto de antropología industrial conducente a su tesis doctoral, en la recién instalada industria Celanese de Zacapu, a recomendación del antropólogo Pedro Carrasco, quien había hecho investigaciones sobre los tarascos durante los años anteriores. Aunque siempre le había atraído la idea de aprender una lengua indígena americana, la razón de trasladarse a Michoacán fue "básicamente por cuestiones monetarias, con lo de la beca no me alcanzaba para ir a Afganistán, que era a donde inicialmente quería ir, para trabajar con pastores turcos". ${ }^{5}$ Sin embargo, esta tierra y su población indígena le proporcionaron un campo de estudio novedoso y rindieron loables frutos profesionales en el corto plazo. Al comenzar el trabajo de campo en la industria, su interés principal se centró en los trabajadores del estrato más bajo de la misma: los indígenas tarascos. Friedrich comenzó a visitar sus comunidades de origen $y$, a partir de las observaciones hechas en el campo, enfocó su interés en otra área "mucho más prometedora y apasionante que la antropología industrial": la antropología política y la historia local, a partir de lo que él llamó el estudio de la "política agraria”. Friedrich se centró en dilucidar las circunstancias históricas y las relaciones contradictorias de poder que condujeron a la revuel-

${ }^{5}$ Entrevista de la autora a Paul Friedrich, Chicago, Il., 28 de junio de 2012. 
ta agraria en el valle de Zacapu, tema que en palabras de Sidney Mintz, su director de tesis doctoral y gran amigo, eran absolutamente "terra incognita". 6

En la introducción de Los Principes de Naranja, Friedrich trae a colación los pormenores y sinsabores del establecimiento inicial de un antropólogo en el sitio elegido, así como los inconvenientes del trabajo de campo que éste y su familia tienen que enfrentar. Una de sus hijas fue mordida por un perro rabioso, mientras que la otra tuvo una infección intestinal que casi le cuesta la vida: "Fue muy duro porque me sentía culpable por lo que les pasó a las niñas, así que pensé que tenía que hacer algo que valiera la pena". ${ }^{7}$ En los documentos contenidos en la Colección Paul Friedrich Papers de la Universidad de Chicago, hay varias cartas familiares y con colegas que refieren con mayor detalle esta situación. Por ejemplo, cuenta que llegó a dormir en un petate o en colchones rebosantes de pulgas: "ya me acostumbré a los piquetes de pulgas, de las cuales está infestado mi colchón", ${ }^{8}$ o que su dieta era fundamentalmente la de un indio tarasco: tortillas, frijoles, maíz y sólo con ocasión de una fiesta, carne, o que tomaba cerveza a la par con sus amigos indígenas: "en la cultura tarasca la cerveza tiene un papel importante para establecer amistades y hablar en confianza". En "Long Days, Short Nights-Letters to my Mother", incluido en el volumen Writing in the Field, Friedrich escribe sobre su vida personal en Naranja en una carta a su madre: "La noche del sábado pasado la recámara estaba llena como siempre, 5 o 6 yardas con 14 inquilinos (hazte una idea); además, la pared está llena de cajas. Las ventajas de esto son: 1. Está templado, 2. Nunca estás solo...". ${ }^{10}$ No obstante que provenía de una familia aristocrática y acaudalada, el joven Friedrich tenía recursos económicos limitados, por lo que acostumbró vestir como los tarascos, calzar huaraches y trasladarse de un lugar a otro en burro o

${ }^{6}$ Paul Friedrich Papers, Special Collections, Universidad de Chicago, caja 11, folder 3.

${ }^{7}$ Entrevista de la autora a Paul Friedrich, Chicago, Il., 23 de octubre de 2012.

${ }^{8}$ Paul Friedrich Papers, Special Collections, Universidad de Chicago, caja 7, folder 1.

${ }^{9}$ Paul Friedrich Papers, Special Collections, Universidad de Chicago, caja 4, folder 4.

${ }^{10}$ Paul Friedrich, "Two Long Walks and Two Short Nights", en Writing in the Field, Festschrift for Stephen Tyler, ed. Ivo Strecker y Shauna LaTosky, 3-5 (Berlín: Lit Verlag, 2013). 
a pie "por eso la gente me tenía confianza, me veían como ellos, además mi situación económica como estudiante no me permitía más". ${ }^{11}$ Friedrich refiere que ayudaba en lo que podía, daba clases de inglés y participaba en las faenas comunitarias, de sol a sol. Incluso dio discursos con motivo de más de una celebración comunitaria. Tal vez por eso, pronto la gente en los pueblos lo conoció como "Tata Pablo", apelativo que sólo se le da a un hombre de mucho respeto y honorabilidad. Se hizo compadre de varias personas en los pueblos tarascos y mantuvo comunicación con ellos durante muchos años después de haber concluido sus estancias en Michoacán.

En las dos temporadas que Friedrich estuvo en Michoacán (1955-1956 y 1967-1969), estableció contacto, intercambió textos y retroalimentación crítica con algunos investigadores estadounidenses participantes del Proyecto Tarasco. ${ }^{12}$ Entabló amistad con Maxwell y Lisa Lathrop, a quienes ha reconocido ampliamente la asesoría que le brindaron en sus estudios de la lengua tarasca. Para Paul, Max Lathrop era un "gran conocedor, un virtuoso" que incluso era famoso por "hablar tarasco mejor que los tarascos". ${ }^{13}$ También conocía personalmente o estaba al tanto de los trabajos en Michoacán de Ralph L. Beals, George M. Foster, Robert West, Mo-

${ }^{11} \mathrm{Su}$ abuelo paterno, Paul Friedrich, fue un profesor y neurocirujano muy distinguido, quien inventó los guantes de látex de uso médico; su abuela paterna descendía de una familia aristocrática prusiana, y tenía título de condesa, con ella Paul tuvo una relación especialmente afectiva y cercana: "era su consentido"; mientras que por el lado materno, su abuelo fue un magnate empresarial del mercado de valores en el Medio Oeste de los Estados Unidos. Su padre, Carl Friedrich, fue el profesor más distinguido de la Universidad de Harvard en su momento, especialista y referencia obligada en Ciencia Política; su madre, una ávida lectora, estudió historia y publicó un artículo sobre el embarazo y el parto (Lenore Pelham Friedrich, "I Had a Baby", Atlantic Montly (abril de 1939): 461465.) Entrevista de la autora a Paul Friedrich, Chicago, Il., 25 de mayo de 2014.

${ }^{12}$ El Proyecto Tarasco fue un proyecto institucional -y veladamente político- de cooperación entre instituciones académicas y gubernamentales mexicanas y estadounidenses con el fin de llevar a cabo investigaciones antropológicas en las regiones indígenas de Michoacán. Tuvo lugar a partir de 1940 y concluyó aproximadamente en 1946. Las principales instituciones que financiaron el proyecto y lo respaldaron académicamente fueron la Universidad de California y el Instituto de Antropología Social del Instituto Smithsoniano, en Estados Unidos, mientras que en México fueron el Instituto Politécnico Nacional y el Departamento de Asuntos Indígenas.

${ }^{13}$ Entrevista de la autora a Paul Friedrich, Chicago, Il., 25 de mayo de 2014. 
rris Swadesh, entre otros, aunque en sus documentos personales en la Special Collections de la Universidad de Chicago no hay constancia de un activo intercambio epistolar. En especial, Paul reconoció y admiró a Swadesh por su cercanía con la gente, su buen humor y el grato recuerdo que había dejado en los pueblos donde trabajó, tanto Naranja como Tiríndaro:

[en Naranja] me presentaron a los funcionarios del pueblo. Fueron cordiales pero reservados [...] y fueron muy amables cuando les dije que conocía sobre Swadesh [...] Muchos exalumnos de Swadesh lo estiman mucho por su personalidad modesta y su liberalismo político [...] es un ejemplo de lo importante y útil que es para el etnólogo, el lingüista y otros visitantes, el dejar una buena impresión. Yo siempre he tratado de seguir esta tradición. ${ }^{14}$

Por otro lado, Friedrich se mostraba un tanto crítico con la antropología de Estado (el Proyecto Tarasco encaja en este concepto en muchos sentidos) y con la manera que se condujeron algunos de sus investigadores en la región tarasca, por ejemplo, al llegar a una comunidad con "séquitos de ayudantes, camionetas lujosas y choferes. Por eso en una comunidad no los aceptaron y los expulsaron a pedradas". ${ }^{15}$ Este rechazo a ciertas prácticas en el trabajo de campo, o bien, su disentimiento con los resultados de algunas investigaciones generadas a partir del Proyecto Tarasco, pueden explicar el hecho de que Friedrich tuviera dificultades en aceptar como válidas las conclusiones de algunos trabajos previos al suyo, específicamente en el caso de Beals y Foster, entre otros. ${ }^{16}$

A nivel más general, Friedrich mantuvo una relación sumamente cercana y enriquecedora -que consta en las múltiples cartas y debates agudos sobre textos y trabajos- con personalidades de la antropología estadounidense, como Sidney Mintz y Clyde Kluckhohn (ambos mentores suyos cuando fue estudiante), Clifford

${ }^{14}$ Paul Friedrich Papers, Special Collections, Universidad de Chicago, caja 11, folder 3.

${ }^{15}$ Entrevista de la autora a Paul Friedrich, Chicago, Il., 25 de mayo de 2014.

${ }^{16}$ Peter Coy, reseña de Paul Friedrich, The Princes of Naranja: An Essay in Anthrohistorical Method. Austin: University of Texas Press, 1986, Journal of Latin American Studies 20(1) (1988): 220-222. 
Geertz o con Victor Turner, su colega en Chicago, quien le escribió una carta donde lo felicita por su "extraordinaria contribución a la antropología simbólica", refiriéndose a su trabajo presentado en el Simposio sobre Simbolismo realizado en Nueva Orleans en $1969 .{ }^{17}$ Por otra parte, Julian Pitt-Rivers, editor del volumen sobre México y América Central de la colección Peoples of the Earth, lo invitó a contribuir en la obra con un tema sobre los grupos indígenas de México. Paul lo convenció de la necesidad de incluir a los tarascos, "un pueblo sumamente interesante y que ha sido seriamente subestimado" ${ }^{18} \mathrm{El}$ resultado fue el texto "The Tarascans" escrito por Paul Friedrich y Margaret Hardin Friedrich, e incluido en la monumental obra sobre los pueblos originarios del mundo. ${ }^{19}$

Sus trabajos sobre Michoacán posicionaron a Paul como uno de los antropólogos más prometedores de la selectiva y competitiva academia estadounidense. Su carrera fue rápidamente en ascenso. Fue instructor en la Universidad de Connecticut (1956-1957), y en Harvard (1957-1958), profesor en Deccan College en India (1958-1959), en la Universidad de Pensilvania (1959-1962), en la Universidad de Michigan (1960-1961), y finalmente, en la Universidad de Chicago (1962 hasta su muerte), donde fue reconocido como profesor emérito de los Departamentos de Antropología y Lingüística, así como del Comité de Pensamiento Social. Además, fue profesor visitante de las Universidades de Indiana, Georgetown y Washington and Lee.

\section{LA ANTROPOHISTORIA Y OTROS TRABAJOS SOBRE MICHOACÁN}

En el caso de la antropología y la historia regional en Michoacán, la obra de Friedrich ha sido pionera y definitivamente continúa vigente porque abrió camino a investigaciones multidisciplinarias y sobre temas nunca antes abordados. Sobre los alcances de sus trabajos sobre los tarascos, señaló: "Vivo con la convicción de que los estudios cui-

${ }^{17}$ Paul Friedrich Papers, Special Collections, Universidad de Chicago, caja 31, folder 4.

${ }^{18}$ Paul Friedrich Papers, Special Collections, Universidad de Chicago, caja 1, folder 16.

${ }^{19}$ Edward Evans-Pritchard, ed., Peoples of the Earth, vol. 4, ed. Julian Pitt-Rivers (Londres: Danbury Press, 1973). 
dadosamente elaborados sobre temas o sistemas desconocidos o poco conocidos constituyen una contribución valiosa a la academia”. ${ }^{20} \mathrm{Al}-$ gunos de sus textos - principalmente sus libros- siguen siendo parte de las lecturas obligadas de los programas en Estudios Latinoamericanos o Historia de América Latina en universidades estadounidenses de prestigio y en algunas más en México y América Latina. ${ }^{21}$

A partir de su trabajo sobre los tarascos, Paul Friedrich construyó un método multidisciplinario, complejo y novedoso que sería influyente con el tiempo al que bautizó como la antropohistoria, que sin embargo, no fue bien recibido en ese momento:

Mientras elaboraba esta propuesta metodológica me sentía solo, no había mucho apoyo para ese camino del pensamiento a finales de los sesenta y principios de los setenta [...] Me decían algunos antropólogos que tratar de escribir en cuatro direcciones al mismo tiempo era una locura. $Y$ a veces era irritante. Una vez una persona reseńó Revuelta agraria como si fuera una novela y no es una novela [...] La gente por lo general no la entendía. Y la mayoría de la gente no comprendía que pudiera además de ser antropólogo general, practicar la poesía y ser poeta. ${ }^{22}$

El método introducido por Friedrich fue tan poco ortodoxo que recibió fuertes críticas, como la expresada por el lector anónimo calificado como "un experto cuyo juicio no puede ser cuestionado" a quien la editora de Yale University Press envió el manuscrito de Revuelta agraria para dictaminarlo. Algunos de sus comentarios sugieren extrema incomodidad con el trabajo de Friedrich, por ejemplo:

No considero que este manuscrito sea publicable. Quizá nunca lo sea [...] El autor ha agrupado cuatro piezas de investigación relativamente sin conexión, muy dispares en importancia, extensión y sofisticación [...] El autor ha intentado usar métodos antropológicos para reconstruir eventos del

${ }^{20}$ Paul Friedrich Papers, Special Collections, Universidad de Chicago, caja 32.

21 "Me anima mucho saber que mi trabajo se lee aún, por ejemplo, en la Universidad de Columbia [...] Mi hija conoció a un profesor muy famoso de historia latinoamericana y le dijo que mi trabajo 'no tiene precedentes y no ha sido superado'. Esto es muy emotivo". Carta de Paul Friedrich a la autora, Chicago, 1 de mayo de 2015.

${ }^{22}$ Entrevista de la autora a Paul Friedrich, Chicago, Il., 23 de octubre de 2012. 
pasado e insertar información etnológica y socioantropológica en un contexto histórico [...] El autor mezcla enormes cantidades de afirmaciones pueriles sobre teoría política y otros temas irrelevantes [...] Muchas preguntas pueden hacerse sobre su método, su metodología y sus conclusiones [...] Sus datos no contribuyen hacia ninguna construcción teórica significativa [...] No creo que éste sea un libro importante [...] No hay un estilo en este libro. En todo el libro no hay una sola frase que sea memorable. ${ }^{23}$

La respuesta de Friedrich ante estos comentarios fue aferrarse aún más a su trabajo y dejar la obra tal y como estaba: "decidí que no reescribiré Revuelta agraria en ningún sentido, y seguiré insistiendo hasta encontrar un comprador". ${ }^{24}$ De hecho, Revuelta agraria fue rechazada por varias editoriales antes de ser finalmente aceptada por la Universidad de Chicago para aparecer al público en 1970. El resto es historia.

En Revuelta agraria en una aldea mexicana, pero especialmente en Los Principes de Naranja, Friedrich demuestra la complejidad de la vida en las pequeñas localidades michoacanas de Naranja y Tiríndaro, desde una posición multifocal. Su método es detallado ampliamente en el apartado sobre los principios de la composición de Los Príncipes de Naranja. Ahí comparte paso por paso el proceso de creación de un sistema multidimensional en su obra a partir de recursos lexicológicos, sintácticos, Gestalt y del grado de simetría. Además, especifica los problemas historiográficos que enfrentó al escribir su obra (lo cual le tomó veinte años) y que el investigador debe tomar en cuenta, de los cuales destacan: tener un conjunto adecuado de evidencia ante una infinidad de hechos; plantear la historia de manera interesante y que refleje su multidimensionalidad; recurrir a diferentes tipos de evidencia y permitir al lector la posibilidad de corroborar; y, finalmente, tener una filosofía propia de la historiografía que afirme la práctica del investigador. ${ }^{25}$ En este texto, desa-

23 "Comentarios a Revuelta agraria en una aldea mexicana de Paul Friedrich, enviados por Yale University Press”, Paul Friedrich Papers, Special Collections, Universidad de Chicago, caja 32.

${ }^{24}$ Paul Friedrich Papers, Special Collections, Universidad de Chicago, caja 32.

${ }^{25}$ Paul Friedrich, The Princes of Naranja. An Essay in Antrohistorical Method (Austin: 
rrolla y comparte una metodología compleja para abordar estudios similares a través del método antropohistórico, el cual consiste en combinar metodologías de diversas disciplinas; por ejemplo, trabajar y registrar en el campo los resultados de la observación participante, hacer entrevistas -con informantes clave o con testigos-, registrar chismes y expresiones del lenguaje, así como cifras de diversa índole y confrontar y complementar esta información con las fuentes históricas tradicionales provenientes de archivos locales, estatales y nacionales; consultar cartas y la historiografía local y regional. En sus textos, Naranja, Tiríndaro y Tarejero (a los cuales a veces se refiere por su nombre y en ocasiones con un seudónimo por cuestiones de seguridad) quedan efectivamente engranados en los contextos locales, regionales y nacionales mediante el método micro-macroscópico que Friedrich usa para dar contexto a su obra.

En general, los trabajos de Friedrich en Michoacán defienden el argumento del autor de que "la antropología se basa en la política", más aún, que la cultura se basa en la política. "Assumptions Underlying Tarascan Political Homicide" 26 es un estudio profundo sobre este tema, a través de la psicología y los conceptos morales de los indígenas participantes en vendettas o asesinatos políticos en un pueblo al que llama "Acán" (Naranja) en el Valle de Zacapu. Friedrich concluye que el homicidio político es consecuencia de la interacción de un conjunto de motivaciones, creencias y justificaciones morales de los lugareños sobre la naturaleza humana (rabia, interdependencia social, lealtad, egoísmo, valor e ideales o ideología y actitudes hacia la muerte), la organización social (igualdad social, diferenciación entre roles de hombres y de mujeres, los vínculos de parentesco ritual y consanguíneo y la lealtad faccional) y la ideología política (solidaridad comunal, justificación de matar a un tirano, agrarismo radical y defensa de la tierra "porque es el símbolo de la vida y el control sobre la tierra es el símbolo más claro del poder"). En este contexto, Friedrich propone que el investigador debe ser

University of Texas Press, 1987), 234. Publicado en español como Paul Friedrich, Los Príncipes de Naranja. Un ensayo de método antropohistórico (México: Grijalbo, 1991).

${ }^{26}$ Paul Friedrich, "Assumptions Underlying Tarascan Political Homicide", Psychiatry: Journal for the Study of Interpersonal Processes 25(4) (noviembre de 1962): 315-327. 
capaz de reconocer el aspecto político de la naturaleza humana desde un entendimiento intercultural para acercarse a la comprensión de hechos que de otra manera resultan inexplicables. ${ }^{27}$

En los artículos "A Tarascan Cacicazgo: Structure and Function"28 y "A Mexican Cacicazgo", ${ }^{29}$ Friedrich analiza el fenómeno hasta ese entonces poco estudiado del cacicazgo en un pueblo tarasco al que llama Durazno (corresponde de nuevo a Naranja). Los textos se articulan con metodologías provenientes de la etnología, la ciencia política y la sociología. Después de proporcionar el contexto histórico reciente de Durazno, a través de cinco etapas diferenciadas, Friedrich aborda las estructuras sociales (familia inmediata, familia ejidal, la casa, el parentesco consanguíneo, la familia política, el parentesco ceremonial y la amistad) que permiten hacer funcionar la política en ese pueblo. Enseguida aborda la caracterización del cacicazgo de Durazno: "El cacicazgo es mucho más que las funciones políticas de las estructuras sociales; es una entidad política distinta con sus propios patrones de acción y su objetivo único de controlar el poder sobre la comunidad, sobre todo el control de la distribución de la tierra" y ejemplifica cómo funciona el faccionalismo en este pueblo: "La facción es el grupo político por excelencia en el pueblo [...] La facción en Durazno es un grupo primario, cara a cara, regido por la discusión informal, la observación mutua y la familiaridad en muchos sentidos" ${ }^{30}$ Insiste en no subestimar el alto grado de libertad política de la gente de Durazno a pesar de vivir bajo cacicazgos "drásticos" ya que casi siempre se observó una oposición activa aún en los periodos de mayor autoritarismo. En este sentido, Friedrich reitera una y otra vez que los cacicazgos son cam-

${ }^{27}$ Por ejemplo, el récord de dos asesinatos por cada mil habitantes al año en la localidad estudiada. Paul Friedrich, "Assumptions Underlying Tarascan Political Homicide", 315-327.

${ }^{28}$ Paul Friedrich, "A Tarascan Cacicazgo: Structure and Function”, en Systems of Political Control and Bureaucracy in Human Societies, Proceedings of the 1958 Annual Spring Meeting of the American Ethnological Society, ed. Ray Verne F. (Seattle: 1958).

${ }^{29}$ Paul Friedrich, "A Mexican Cacicazgo", Ethnology 4(2) (abril de 1965): 190-209. Este texto incorpora una revisión del artículo de Paul Friedrich, "A Tarascan Cacicazgo: Structure and Function".

${ }^{30}$ Paul Friedrich, "A Mexican Cacicazgo", 198. 
biantes en sus formas y organización: "No son variedades de una forma estable, sino que tienden a oscilar entre los dos extremos de la centralización autocrática, bajo un cacique, y el choque antagónico entre familias políticas y sus subdivisiones cambiantes" ${ }^{31}$ Finalmente, explica los métodos mediante los cuales los líderes de Durazno han alcanzado el "éxito": la persuasión verbal (argumentación y oratoria, intriga y astucia); la organización humana (habilidad para reclutar seguidores y manejarlos); y, finalmente, el método de la violencia (homicidios perennes, pero no sádicos que son vistos como una dimensión inevitable de la política).

Por otra parte, en "El parentesco y la política en una aldea mexicana", ${ }^{32}$ Friedrich desentraña las funciones políticas de las formas esenciales de la sociedad a través de la familia inmediata, la familia ejidal, la "casa" y la familia política. En un pueblo al que en esta ocasión vuelve a llamar Durazno (Naranja), analiza la determinación de la política del mismo a través de estructuras de parientes alojados en condiciones de proximidad personal, los cuales se deben lealtad, principalmente cuando los vínculos son consanguíneos. Refiriéndose al caso de Naranja en las décadas de 1920 y 1930 señala: "La afiliación por las mujeres es una base potente para la alianza política, porque los hijos adquieren de su madre las ideas de lealtad concreta y personal, y algunos de los valores genéricos que determinan el comportamiento político". Posteriormente, analiza a la "familia política" como una categoría cuyas funciones son casi enteramente políticas y cuyos miembros se deben reciprocidad. Finalmente, explica las funciones políticas de los amigos "de confianza" y de los parientes rituales, cuyo vínculo es sentimental y casi sagrado y demuestra cómo el compadrazgo sirve para crear nuevas alianzas de apoyo o fortalecer las existentes, así como subsanar las fallas en las redes de parientes naturales. Friedrich concluye que el compadrazgo relaciona a los líderes del pueblo horizontal y verticalmente con los políticos de otros pueblos y de nivel estatal; mientras que la relación de amistad íntima es un vínculo más flexible que el compadrazgo,

${ }^{31}$ Ibid., p. 202.

${ }^{32}$ Paul Friedrich, "El parentesco y la política en una aldea mexicana”, en Memorias del XXXVI Congreso Internacional de Americanistas (Sevilla: 1966), 423. 
que se da únicamente entre cinco o seis personas y, por lo general, implica apoyo mutuo. Su conclusión es que

todas las estructuras culturales implican deberes y un contenido afectivo que se combinan por lo usual, sin demasiadas contradicciones para determinar el comportamiento político. Hasta cierto grado, las escisiones y la cooperación entre partidos es sólo la síntesis de envidias y afinidades entre estas pequeñas unidades de parentesco. ${ }^{33}$

Los estudios de los líderes de los pueblos del valle de Zacapu y sus relaciones afectivas, políticas, sus historias de vida, entre otros, son ambiciosos e incluyen interpretaciones complejas sobre los rasgos del carácter y la personalidad (incluyendo las características físicas, la historia sexual, matrimonial y familiar) de cada individuo. Friedrich recurre constantemente a interpretaciones psicológicas a través de las pruebas de Rorschach y de la teoría freudiana, pero más aún a los postulados del movimiento de Cultura y Personalidad, así como de la psicología humanista. Pero, consistente con su modelo antropohistórico, más que elaborar análisis psicológicos completos de estos personajes, lo que Friedrich hace es utilizar los datos psicológicos obtenidos para enriquecer la interpretación de las historias de vida que presenta. Al utilizar herramientas y métodos provenientes de diversas disciplinas y enfoques, Friedrich buscó delinear un retrato de la personalidad de sus informantes lo más cercano a la realidad. En este sentido, en sus análisis de los siete príncipes naranjeños se apoyó en los resultados de las pruebas y los tests aplicados. En la colección de Chicago se resguardan las tarjetas de Rorschach, los tests psicológicos y las anotaciones hechas por Friedrich en el campo. En especial, llamaron mi atención las preguntas y las respuestas esperadas en las llamadas pruebas de "inteligencia" de WechslerBellevue, que me parecen más de cultura general occidentalizada que de inteligencia. Las respuestas "incorrectas" de los tarascos de alguna manera debieron incidir en los resultados y las interpretaciones que se desprendieron de éstas.

${ }^{33}$ Ibid., p. 428. 
En sus trabajos, Friedrich considera una amplia multiplicidad de factores para explicar la historia que cuenta: la existencia de una oligarquía constituida por los "príncipes y sus aliados" (quienes controlan el poder local municipal y ejidal y que a su vez se vincula estrechamente con las organizaciones políticas estatales y nacionales y con las logias masónicas), que se mueve motivada por el "deseo irreprensible de dominar", ante lo cual se generan escisiones y faccionalismos que en muchas ocasiones desembocan en el asesinato de los rivales, tal como estudia detalladamente en "Assumptions Underlying Tarascan Political Homicide". ${ }^{34}$ Lo anterior se enmarca en explicaciones de factores económicos como las relaciones de producción y los patrones de consumo. Pero no sólo eso, sino que reconoce la interacción con la "cultura" como símbolos y significantes organizados, los factores psicológicos de la emoción, el carácter y la cognición, y las ideologías explícitas o implícitas con que la gente ordena sus vidas políticas. En "Revolutionary Politics and Communal Ritual", ${ }^{35}$ analiza los patrones y relaciones informales que determinan y controlan las decisiones de una comunidad. Que, en el caso de las comunidades pequeñas, se resuelven mediante las "técnicas y mecanismos" del compadrazgo y del faccionalismo local. En este trabajo vuelve a enfatizar la importancia del ritual y de la ideología, y en particular, cómo Primo Tapia y otros líderes emplearon, o mejor dicho, explotaron los sistemas de fiestas para propagar su ideología mixta de agrarismo, comunismo y anarquismo para debilitar la influencia del clero en la política local.

De manera general, las diversas temáticas y enfoques de Friedrich han mantenido un hilo conductor que él llama un "triángulo de acercamientos" abstractos y concretos. Uno de los enfoques se refiere a combinar la teoría de la cultura (abstracto) con la etnografía rasa (concreto); otro enfoque tiene que ver con el lenguaje (igualmente incluye un nivel concreto y uno abstracto representado en las teorías del lenguaje); y, finalmente, incluye la poesía (su nivel con-

${ }^{34}$ Paul Friedrich, "Assumptions Underlying Tarascan Political Homicide".

${ }^{35}$ Paul Friedrich, "Revolutionary Politics and Communal Ritual", en Political Anthropology, ed. Marc J. Swartz, Victor W. Turner y Arthur Tuden, 191-220 (Chicago: Aldine Publishing Company, 1966). 
creto son los poemas y, el abstracto, las teorías de la poesía). En sus estudios sobre Michoacán, Friedrich considera indispensable recurrir no sólo a los métodos antropológicos tradicionales, sino a enriquecer los descubrimientos del investigador a través de la historia local, la historia oral (a la que considera en parte una expresión poética), la macrohistoria, la sociología, la economía, la biología, la psicología, la ciencia política, la música, la literatura, la lingüística, la poesía y otros campos de estudio. ${ }^{36}$ Insiste también en la importancia de los factores ambientales en la determinación de la historia y de la cultura que se estudia.

Como investigador y como profesor, Friedrich desquebrajó paradigmas. Fue contracorriente demostrando que no hay que apegarse a las formas tradicionales de decir o analizar las cosas, ni a los métodos de investigación aceptados: hay que innovar y "escarbar dentro del alma” para poder producir un estudio que sea significativo para la persona que lo lleva a cabo.

\section{FRIEDRICH Y UNA “NUEVA ETNOGRAFÍA”}

Las investigaciones de Paul Friedrich sobre los tarascos pueden considerarse como pioneras en el uso de métodos que después serían ampliamente utilizados por lo que hoy se conoce como "nueva etnografía”, es decir, de un momento en la antropología que exigió mayor autorreflexión y crítica, cuestionando los modelos tradicionales de representación e integrando la perspectiva del investigador como un actor más en el trabajo de campo. ${ }^{37}$ Aunque Friedrich rechazó ser catalogado como "posmodernista", ${ }^{38}$ es indiscutible que

${ }^{36}$ Paul Friedrich, The Language Parallax. Linguistic Relativism and Poetic Indeterminacy (Austin: University of Texas Press, 1986), 143.

${ }^{37}$ En la "nueva etnografía" se empleaban estrategias reflexivas que incluyeron trabajos sobre las diferencias culturales enfatizando el rol de las interacciones intersubjetivas, el escrutinio de los sistemas globales de dominación a través de manifestaciones simbólicas en las vidas de los individuos, la experimentación de formas retóricas etnográficas tradicionales o la relectura de textos clásicos de la antropología como precursores de la nueva etnografía. Frances Mascia-Lees, Patricia Sharpe y Colleen Ballerino Cohen, "The Postmodernist Turn in Anthropology: Cautions from a Feminist Perspective", Signs 15(1): 8.

${ }^{38}$ No existe un consenso sobre el significado del término "posmodernismo" en antro- 
abrió camino a nuevos enfoques antropológicos al confeccionar un método holístico, extremadamente complejo, para abordar sus temas de estudio. Su método es una síntesis de la antropología general (arqueología, etnografía, lingüística y antropología física), los postulados de "Cultura y personalidad" (especialmente a través de la influencia de Sapir y Linton, quienes fueron sus mentores), con la teoría política y el humanismo filosófico (la influencia de su padre y, en especial, las relecturas de El Príncipe de Maquiavelo aplicadas al contexto local en el valle de Zacapu), la historia (el modelo de Tucídides, entre otros) y la literatura (inspirado principalmente en los grandes escritores rusos, como Tolstoi), abordados desde una postura honesta con respecto a los factores personales que influyeron y afectaron su trabajo.

La influencia de los trabajos de Friedrich a la "nueva etnografía" se da en el sentido de que éstos proponen una nueva relación entre el investigador, el lector y el objeto de estudio de la antropología (la gente de la comunidad), en la que a las personas de la comunidad estudiada se les concede un nivel intelectual/educativo/cultural en el cual se vuelven factibles de interactuar con el investigador, e incluso de contradecir las interpretaciones o caracterizaciones que este último ha desarrollado. ${ }^{39}$ En este proceso, el antropólogo adquiere un

pología. Es un concepto polémico y tan heterogéneo que se utiliza ampliamente pero con significados muy diversos e, incluso, contradictorios. En este texto empleo antropología "posmoderna" o "posmodernista" para referirme a las investigaciones tendientes a cuestionar la autoridad del académico o científico, a observar y aceptar la construcción y relatividad de todo discurso, así como la incorporación de múltiples voces e interpretaciones a la investigación, contradiciendo las tendencias totalizantes y universalistas. Véase James Clifford y George E. Marcus, Writing Culture, The Poetics and Politics of Ethnography (Berkeley: University of California Press, 2010); Paul Rabinow, Reflections on Fieldwork in Morocco (Berkeley y Los Ángeles: University of California Press, 1977), así como Renato Rosaldo, Culture and Truth. The Remaking of Social Analysis (Boston: Beacon Press, 1993).

${ }^{39}$ Una anécdota en este sentido es la manera en que Friedrich se enteró de la muerte de Albert Einstein en Cherán: "Mientras tres campesinos hablaban de la posibilidad de una Tercera Guerra Mundial, yo les expliqué que un judío alemán había sido el primero en formular las teorías de la bomba atómica [...] 'Si, pero ese Einstein murió ayer', me dijo uno de los campesinos y sacó un periódico de su bolsillo y me enseńó el editorial sobre 'El Padre de la Bomba Atómica'. Yo quedé sorprendido del nivel de información sobre los acontecimientos mundiales que encontré en ese pueblo". Paul Friedrich Papers, Special Collections, Universidad de Chicago, caja 9, folder 19. 
rol de considerable importancia al cuestionar el papel de la propia antropología en el mantenimiento de la hegemonía occidental en todos los campos del conocimiento, resaltando que cada texto etnográfico es una construcción cultural única e irrepetible. Friedrich postula que la teoría lingüística y antropológica deben reconocer al hablante nativo y al analizador, al observador participante. En The Language Parallax, Friedrich señala repetidamente que el observador es siempre un participante: "No hay universo sin su observador, ni observador que no sea parte del universo de la descripción" ${ }^{40} \mathrm{y}$ luego postula "La voz del antropólogo es sólo otra voz. Todos somos 'nativos". ${ }^{41}$ Friedrich propugna por la incorporación de las múltiples voces presentes en el trabajo etnográfico al resultado final del mismo, contradiciendo la autoridad única del antropólogo. Antes aún que la "nueva etnografía", reconoce que hay una relación asimétrica entre el etnógrafo y el objeto de estudio en cuanto al conocimiento, al poder y a la movilidad estructural y que en cualquier momento, el etnógrafo puede malinterpretar e incluso manipular a las personas a las que está estudiando; por lo tanto, el resultado de la investigación es siempre la interpretación del investigador y no la de las personas estudiadas (aunque se reconozca explícitamente la influencia de éstos). ${ }^{42}$ El trabajo de Friedrich explora nuevas técnicas de investigación y redacción en sus textos, exponiendo las relaciones de poder subyacentes en el quehacer etnográfico y produciendo resultados novedosos en varios sentidos. Por otro lado, su trabajo ha sido sensible a las diferencias culturales y a la multiplicidad y significado de la experiencia individual en la construcción de las mismas. En The Language Parallax, Friedrich enfatiza la importancia de la indeterminación y la imaginación individual, pero considerando que ésta crece y se nutre del diálogo con los otros, por lo cual siempre implica pluralismo. ${ }^{43}$

${ }^{40}$ Paul Friedrich, The Language Parallax, 124.

${ }^{41}$ Paul Friedrich, "Multiplicity and Pluralism in Anthropological Construction/ Synthesis", Anthropological Quatery 61(3): 103.

${ }^{42}$ Frances Mascia-Lees et al., "The Postmodernist Turn in Anthropology", 21.

${ }^{43}$ Paul Friedrich, The Language Parallax, 3. 
Friedrich, siendo él lingüista profesional y experto en diversas lenguas, señaló repetidamente la intraducibilidad de éstas y, por lo tanto, la imposibilidad de la comprensión de las culturas: ${ }^{44 ~ " H a y ~}$ una continuidad universal entre la poesía y la referencia en la lengua, y ésta es otra fuente de la autenticidad -originalidad- de las lenguas y la relativa intraducibilidad entre ellas" ya que "el lenguaje nunca es exclusivamente un código estrictamente lógico de símbolos inequívocos" ${ }^{45}$ Es decir, enfatizó una y otra vez que nuestro entendimiento de toda aquella cultura (e idioma) que no sea la propia inevitablemente es parcial, e incluso, miope. Dicho de otro modo, las interpretaciones que el investigador hace de la cultura ajena siempre estarán sesgadas por la propia identidad cultural. Por todo ello, es que hay quienes ubican el trabajo de Friedrich dentro del campo del posmodernismo, o más bien, de los múltiples posmodernismos. ${ }^{46}$

En Los Principes de Naranja, el Tao del Lenguaje, The Language Parallax, entre otras obras y en sus documentos personales, Friedrich dedica muchas páginas a situarse como persona antes que investigador dentro de una cultura específica, a rememorar episodios de su vida que influyeron decisivamente en sus interpretaciones de las culturas ajenas (sus múltiples viajes desde pequeño a Europa, posteriormente a Asia y a México) a compartir con el lector-quizá buscando la empatía- las vicisitudes y obstáculos del trabajo de campo, así como las tragedias de su vida personal (la muerte de sus seres queridos o sus problemas de salud). Aunque no es explícito en sus textos con respecto a sus problemáticas familiares, sí lo es en la correspondencia personal resguardada en la colección de Paul Friedrich Pa-

${ }^{44}$ Por cultura Friedrich se refiere a "un sistema de significados, valores, símbolos y patrones emocionales abierto, en constante evolución y orientado hacia metas específicas, el cual se transmite por miembros de una sociedad", y también "un punto de vista sobre las cosas, y más precisamente, a los significados y patrones compartidos y transmitidos por uno o más individuos, significados que pueden ser sensoriales o prácticos, abstractos e ideológicos". Paul Friedrich, The Language Parallax, 20 y 74.

${ }^{45}$ Paul Friedrich, The Language Parallax, 125 y 126.

${ }^{46}$ A partir de 1960, los movimientos posmodernistas han cuestionado básicamente los "dados por hecho" y las verdades absolutas impuestas por las potencias occidentales. Frances Mascia-Lees et al., "The Postmodernist Turn in Anthropology”, 15. 
pers, que él mismo decidió que permanezca sin restricciones para consulta pública. A través de ella, el lector puede percibir el impacto emocional causado por sus problemas familiares y las preocupaciones por el bienestar de sus hijos y cómo estos hechos tuvieron repercusiones profundas en su labor como antropólogo y poeta.

Inevitablemente, el lector de Friedrich se queda con la sensación de estar recibiendo información demasiado sensible, íntima. Pero ésa debe ser la intención de Friedrich y una de sus mayores virtudes: situar al antropólogo como una persona con una historia de vida propia, que decide compartir su experiencia con el lector para que éste pueda tener más elementos de análisis sobre el trabajo que se le está presentando, adelantándose quizá a las interpretaciones y a las conclusiones del mismo. Este ejercicio ha sido sumamente innovador y sigue siendo inusual en la práctica académica por cuanto despoja al investigador encumbrado de ese halo de inafectabilidad mundana y lo sitúa en un terreno ampliamente vulnerable. Mediante diversas estrategias que usa para desmitificar al "otro", Friedrich se desmitifica a sí mismo.

Friedrich, al igual que los antropólogos llamados "posmodernos”, muestra en su trabajo que la cultura está compuesta de códigos y significados seriamente cuestionables, que la lengua y la política son inseparables y que la construcción del "otro" implica relaciones de poder y hegemonía, es decir, de dominación, de la cual él mismo no puede escapar al ser parte de la "crème de la crème" de la academia estadounidense, ya de por sí elitista y mayoritariamente blanca y de varones.

\section{El POETA ETNÓGRAFO Y EL ETNÓGRAFo POETA}

No se porqué no es usual todavía conectar la poesía con la etnografía. Se puede hacer etnografía rasa, como es, historia y datos factuales, pero luego está la poesía. Me parece que se le puede dar este tipo de tratamiento. La poesía es una forma muy condensada [...] mucho más sucinta y profunda que la prosa, por eso me gusta. ${ }^{47}$

${ }^{47}$ Entrevista de la autora a Paul Friedrich, Chicago, Il., 23 de octubre de 2012. 
La lengua es una infinidad de poemas potenciales esperando ser moldeados por el individuo. El lenguaje es, en ese sentido, un borrador de la poesía, tanto como la poesía es el libro de muestra del lenguaje. ${ }^{48}$

En el año 2013, en el marco de la 112a Reunión Anual de la American Anthropological Association, tuvo lugar un simposio dedicado a la influencia del trabajo de Paul Friedrich entre varios lingüistas y antropólogos, en el cual se reconoció el legado "friedrichano" como uno de los "maestros de la antropología" en explorar el poder de la poesía para "balancear la ecuación humana", "para resolver la incertidumbre" y para "cantar el orden social". ${ }^{49}$ Este tipo de poesía, profunda y compleja, está presente a lo largo del trabajo de Paul y es una de sus principales contribuciones. Como señala James Fernandez, siguiendo a Bentham: "la ficción crea hechos que son, a fin de cuentas, ficciones trabajando en el mundo [...] Si la cultura es ficción, o en el grado en que es ficción, inevitablemente se requiere un enfoque poético para estudiarla y comprenderla [...] Esto es lo que ha hecho Paul y lo que le da tanto poder a su poesía". ${ }^{50}$ James Redfield, amigo y colega de Paul Friedrich en Chicago e hijo del famoso antropólogo Robert Redfield, también escribió hace varios años sobre Paul como etnógrafo y poeta. ${ }^{51}$ En su texto señala que a través de la experiencia de campo - The Field-el etnógrafo se convierte en un extraño que trata de encajar en el medio que lo rodea, incómodo por la ignorancia que lo envuelve. La etnografía entonces es un estado alterado, sobre todo al principio, antes de que las cosas empiecen a hacer sentido. Esta experiencia es la parte poética de la etnografía, en la cual el etnógrafo, como Friedrich, puede hacer poesía a partir de sus momentos de ignorancia motivada. La poesía sirve a la antropología

${ }^{48}$ Paul Friedrich, “The Master Trope. The Poetic Polarity: Music”, Dialectical Anthropology (11) (1986): 325.

${ }^{49}$ James Fernandez, "Poetry, Power, and the Social Imagination", en el simposio dedicado al trabajo de Paul Friedrich en la 112a Reunión Anual de la American Anthropological Association, Chicago, 2013. Agradezco al profesor Fernandez haberme facilitado una copia de su texto.

${ }^{50}$ Idem.

${ }^{51}$ James Redfield, "Paul Friedrich: Ethographer as Poet and Poet as Ethnographer", Dialectical Anthropology (11) (1986): 351-354. 
como un medio de transformación, "trae todo a la vida. Es esa forma de vida la que convierte todo en lenguaje; es una forma de arte mucho más amplia y poderosa que lo que se pueda decir". ${ }^{52}$ Friedrich, siendo uno de los mayores representantes de la antropología poética, mostró que la etnografía es en gran medida ficción, que es algo construido, confeccionado y nunca absoluto y que la poesía puede no sólo ser informativa y útil sino inspiradora para la ciencia. ${ }^{53}$

Friedrich reconoció que los trabajos de Edward Sapir y Roman Jakobson inspiraron e influenciaron sus propios estudios, pero proponía superar sus postulados intentando "trascender el lenguaje por medio del lenguaje", traspasando sus límites y los marcos culturales donde está inmerso el antropólogo. Para Friedrich, la poesía puede dotar a la antropología de apreciaciones invaluables acerca de los sentimientos más intensos del individuo, ya sean éstos personales o estén codificados culturalmente. Para él, un investigador debe confrontar, internalizar y representar los sentimientos y las emociones de las personas que estudia apoyándose en un método de estudio horizontal, esto es, la analogía que se convierte en "el proceso más poderoso en el lenguaje, la cultura y la personalidad". ${ }^{54} \mathrm{Y}$ entonces, aboga por incrementar el realismo y la sensibilidad del investigador al explotar el uso de otros sentidos, además del visual, por ejemplo, el auditivo (indispensables en la lingüística y la poética), pero también el gusto y el tacto e incluso el olfato y encaminarse a lo que denomina una antropología más sensorial y sensual. ${ }^{55}$

En este tenor, resultan especialmente interesantes los poemas considerados "experimentos antropológicos" que realizó Friedrich

52 Brady apud en Meschomic (1988, 90) y (Vnedler 1988, p. 6). Ivan Brady, ed., Anthropological Poetics (Nueva York: Rowman and Littlefield Publishers, 1991), 961.

53 Paul Friedrich, junto con Iaian Prattis y Stanley Diamond, abrieron camino a la publicación de poesía etnográfica en los journals académicos antropológicos. Poemas de Friedrich se publicaron en American Anthropologist, en Cross-Cultural Poetic y en Qualitative Inquiry, por citar sólo algunos. Ivan Brady, ed., Anthropological Poetics, 961.

${ }^{54}$ Paul Friedrich, "Return to Yale or Toward an Essay on Analogy", charla presentada en la Universidad de Yale, 2007. Texto inédito facilitado por el Prof. Friedrich a la autora.

${ }^{55}$ Paul Friedrich, "Multiplicity and Pluralism in Anthropological Construction/ Synthesis", Anthropological Quatery 61(3): 105. 
centrándose en su trabajo de campo entre los tarascos. ${ }^{56}$ En ellos, recurrió a la etnografía para tratar temas universales. Desde mi punto de vista, los mejores ejemplos de la poesía de Friedrich sobre motivos michoacanos se inscriben en esta conceptualización: la maravilla de ir descubriendo al otro, de escuchar nuevos sonidos, apreciar nuevos colores y paladear sabores nunca antes imaginados desde una postura que lo incluye analógicamente como parte del universo que observa. Su primer poema en Michoacán trata sobre el color y la forma de las frutas que acababa de conocer:
Las tostadas fibras del mamey
Que hay que tentar antes de comprarlo
Los blancos y melosos grises de la chirimoya
Los claros matices de la granada
Madurados por el sol, no resecados,
Tan perfectos como transitorios ${ }^{57}$

En otra muestra, llena de romanticismo y curiosidad, narra su primer encuentro con los indígenas michoacanos al estilo del género japonés haibun, en el que se entremezclan poesía y prosa una y otra vez, en "El Tao del Lenguaje" y un fragmento del mismo en Los Principes de Naranja:

Iba yo disfrutando el hermoso viaje en autobús de Morelia a Zacapu y acabábamos de pasar la fuerte pendiente en el sinuoso camino que sube hasta el alto cerro, cuando, como escena de postal suiza, apareció el Lago de Pátzcuaro: sus apacibles aguas azules, rodeadas de montañas, los delgados muros de piedra que descienden hasta la orilla a través de campos de trigo verde pálido, donde los pescadores, apenas visibles, están colgando sus redes y, luego, como centro de esta gema de óxido azuloso, bañada de sol, el pueblo de Pátzcuaro, anidado en una semi península, con sus casas

${ }^{56}$ Stephen A. Tyler, "The Poetic Turn in Anthropology: The Poetry of Paul Friedrich”, American Anthropologist 86(2) (junio de 1984): 332.

${ }^{57}$ Paul Friedrich, "El Tao del Lenguaje", en Fundamentos de Antropología (Granada: Diputación Provincial de Granada, Centro de Investigaciones Etnológicas Ángel Ganivet, 1994), 65. 
bajas café claro y arena y la torre puntiaguda de su única iglesia. Apenas íbamos perdiendo de vista este panorama a medida que descendíamos por otro valle de campos ondulados y burros que comían rastrojos, cuando noté que la velocidad del autobús disminuía y que un grupo de tres mujeres nos hacía señas al borde de la carretera. Mientras subían al autobús, me fijé en el pelo despeinado y los grandes y plácidos ojos de los niños que dos de ellas cargaban envueltos en sus rebozos azul oscuro y negro. Una de estas madres, de unos cuarenta años, tenía una cara cobriza muy arrugada, el pelo negro, polvoriento, con raya en medio y recogido en un chongo pequeño, y unos centelleantes ojos negros ligeramente inyectados. La otra madre tenía un aspecto similar aunque sólo aparentaba veinticinco años; tenía los dientes casi salidos y su piel era mucho más clara. La tercera, una muchacha de unos catorce años, también mostraba dientes grandes, su piel era casi negra, quemada por el intenso sol de México. Ella también iba descalza y llevaba un vestido de algodón azul claro y un grueso rebozo alrededor de los hombros. Las tres parecían fuertes, serenas y autosuficientes. Llegaron hasta la parte de atrás del autobús, donde yo estaba sentado, la adolescente pasó hasta el fondo y la madre joven se quedó de pie junto a mi asiento. La mayor bajó al niño de su espalda y, mientras se acomodaba en el asiento que estaba detrás de mí, noté que llevaba una especie de falda que le colgaba por detrás, un trozo de fieltro negro muy plisado. Miré a mis vecinas con lo que me pareció una combinación ideal de curiosidad y discreción pero sólo pensé para mis adentros: "Son indias". Esto ya era emocionante en sí y ya había yo experimentado una vívida sensación al rozarme el fieltro negro de mi vecina mientras se sentaba. Entonces, casi al mismo tiempo, me di cuenta de que la mujer mayor no había entendido las palabras del cobrador y, como clímax y quintaesencia de toda la América aborigen perdida, oí (ya en medio del estruendo del autobús) los dulces y absolutamente exóticos sonidos de la lengua tarasca del este que nos da nombres con sonidos chinos como Tzintzuntzan. Me volteé y miré por la ventana el veloz paso de los campos. "Así que éstos son mis tarascos", me dije muy feliz, "me gustan sus caras". ${ }^{58}$

${ }^{58}$ Paul Friedrich, "El Tao del Lenguaje", 66; y Paul Friedrich, The Princes of Naranja, 247 y 248. 
Cada uno de los poemas de Paul cuenta una historia y, casi siempre, muestra sus apreciaciones personales, siguiendo una estructura asociativa: sus poemas parecen señalar que "lo que estas cosas tienen en común es que todas pertenecen a una mente que conoce su propio mundo [...] y que inevitablemente el poeta sabe que sabe más de lo que puede expresar con palabras". ${ }^{59}$ El momento del proceso genérico humano mediante el cual se pueden sostener varios niveles de información al mismo tiempo mientras el individuo se concentra en uno o dos a la vez es llamado "multiple tracking" por Friedrich. ${ }^{60}$ En este sentido, reitera una y otra vez que la única realidad de la lengua es el aquí y el ahora: "el lenguaje hace presente todo lo que contiene [...] contiene su pasado y su futuro, así como su presente y contiene su tiempo y sus procesos dentro de sí mismo, cuestionando así la 'linealidad' de las lenguas". 61 ' $€$ ste es el caso del poema "Cena en Zamora", en el cual Friedrich cuenta lo que pasa en varias mentes a partir de la mente del poeta, centrándose en dos experiencias universales: la experiencia sensorial y el apetito, e involucrándose emocionalmente como observador participante en un hecho que acaba de presenciar.

El gato entre los tulipanes acecha a su presa:

Cuervo, rata, otro gato, quizás,

Imaginado por la joven artista del autobús,

Su cuaderno de dibujo bajo el brazo, ella misma

Un boceto de Miguel Ángel, que mira más allá

Del gato los reflejos asimétricos,

La rielante flor de lis del lago,

El callejón bajo la ventana de su hotel

Esa tarde de domingo en Zamora, México;

Oyendo, una vez más, ese llanto

Inextirpable del vendedorcito de la plaza

Mientras los dos ayudantes del barbero ríen

$\mathrm{Al}$ arrebatarle el último pan dulce de la charola

${ }^{59}$ James Redfield, "Paul Friedrich: Ethographer as Poet”, 352.

${ }^{60}$ Paul Friedrich, The Language Parallax, 129.

${ }^{61}$ Paul Friedrich, The Language Parallax, 133. 
El pequeño vendedor al que esa tarde de domingo vi llorar su cena perdida parecía indígena: tal vez era un huérfano refugiado o tal vez venía de alguno de aquellos hogares destruidos de los pueblos al sur de Zamora, desgarrados por la vendetta. Como Zamora, esos pueblos presencian todo lo que les toca de la inhumanidad del hombre hacia el hombre y hacia la mujer. Me sentí involucrado en lo que había presenciado. ${ }^{62}$

En el poema "Novia indígena" Friedrich condensa más de "dos mil palabras de descripción científica de mi Revuelta agraria en una aldea mexicana”. Las primeras dos líneas, por ejemplo, resumen el primer párrafo de aquella:

cerca de la mitad de los padres arreglaba de antemano el matrimonio de sus hijos antes de que llegaran a la adolescencia. Otros matrimonios ocurrían después de un periodo de cortejo y una solicitud formal por parte de los padres del joven. Los adolescentes podían estar motivados por el afecto mutuo, pero lo que consideraban los padres era la virtud y los factores económicos. Entre los 14 y 18 años los jóvenes cortejaban a muchachas de 13 y 14 años. El cortejo se hacía a lo largo de las veredas que conducían al vecino ojo de agua y las muchachas se vestían con sus mejores ropas antes de salir en pequeños grupos durante la tarde; el simbolismo del cántaro de la muchacha desempeñaba un papel crucial en las apresuradas conversaciones y en las proposiciones expresadas en formas tradicionales. ${ }^{63}$

\section{Novia indígena ${ }^{64}$}

Lucir mi blusa bordada y llevar un cántaro en los hombros.

Dejar que me pida con las palabras antiguas en camino al ojo de agua. Acercar a mis labios y a mi corazón un colibrí, muerto por un tiro suyo. Ver el vaivén, las entradas y salidas de la casamentera que sella nuestra unión. Oír a sus padrinos que se juntan ante mi padre y al "vocero" que aplaca su coraje fingido.

Arrodillarme sobre un tapete de fragante junco ante una mesa con velas y la imagen de San José.

${ }^{62}$ Paul Friedrich, "El Tao del Lenguaje", 65.

${ }^{63}$ Ibid., p. 67.

${ }^{64}$ Ibid., p. 66. 
Sentir detrás de nosotros cómo se congrega nuestra gente con sus rebozos azules y sus sarapes brillantes.

Recibir a sus padres que cargan doce canastas de pan y una jarra de ron de caña.

Llevar a sus padrinos y madrinas una olla de atole para bajarles la borrachera.

Desfilar con la banda por el pueblo, mientras la gente nos mira desde su puerta.

Servir un gran pozole de cabeza de puerco con maíz y salsa de muchos chiles.

Bailar la kupera con mis hermanas y primas alineadas detrás de mí.

Irme acercando a sus primos y hermanos en fila detrás de él, con sus espadas y machetes.

Bailar yo hasta él, él hasta mí, y rasguñarnos las mejillas con rosas.

Trenzar los codos al beber el ron.

"La noche de la raíz" después y "aprender a vivir".

Hacerle tortillas, criar hijos, ser una familia.

Como señala Redfield, si el poeta tiene un conocimiento peculiar, ése es el conocimiento del lenguaje. Esto significa que un poeta etnógrafo sabe hacer algo bello a partir de lo que conoce a través del trabajo de campo. En el caso de Paul Friedrich, quien poseía un vasto conocimiento de las lenguas y de la lingüística, esto le permitió hacer poemas de las lenguas y la lingüística, o de la experiencia del trabajo de campo y la etnografía. ${ }^{65}$ Para Paul, la poesía constituía un medio alternativo a las concepciones representacionistas de la lengua en la cultura. ${ }^{66}$

La poesía de Paul Friedrich está "encantada por las manifestaciones de fuerzas más allá de nuestro control" ${ }^{67}$ y refleja de una manera sensible lo que sus extensos trabajos sobre la gramática del tarasco ${ }^{68}$

${ }^{65}$ James Redfield, "Paul Friedrich: Ethographer as Poet", 353.

${ }^{66}$ Johannes Fabian, "The Other and Anthropological Writing", Critical Inquiry 16(4) (verano de 1990): 766.

${ }^{67}$ James Redfield, "Paul Friedrich: Ethographer as Poet", 351.

${ }^{68}$ La perspectiva de su investigación sobre la lengua tarasca, le ocasionó un desencuentro con Mary Le Cron Foster, otra de las estudiosas más reconocidas de la materia. Friedrich realizó una reseña muy crítica del trabajo de Foster, después de su publicación 
desarrollan ampliamente como: The Tarascan Suffixes of Locative Space: Meaning and Morphotactics, ${ }^{69}$ "Dialectical Variation in Tarascan Phonology", 70 "Metaphor-like Relations Between Referential Subsets"71 o "Prolegomena to Tarascan"..$^{72}$ A partir de su trabajo lingüístico en San José y Cocucho, Michoacán, Friedrich produjo lo que él mismo consideró "una dialectología que es la más completa de cualquier lengua del Nuevo Mundo e incluye soluciones a muchas partes del sistema de vocales y consonantes". ${ }^{73}$ Analizar sus obras sobre la lengua tarasca escapa del objetivo de estas páginas, pero es interesante señalar algunos de sus postulados, invitando al lector a consultarlas detenidamente. Por ejemplo, Friedrich explica que en ella el cuerpo funciona como un modelo general o punto de partida de la imaginería más diversa, como una especie de analogía anatómica del mundo ${ }^{74}$ Los significados corporales de cuello y garganta se relacionan con expresiones de deseo, placer, codicia, sed, pena y coraje o que "todas las ideas e imágenes, estómago, genitales, campo, patio, se conectan con geometrías de extensión y psicologías del enfoque emotivo, que son universales". Específicamente, en The Language Parallax, Friedrich dedica varias páginas a desarrollar una argumentación sobre el potencial poético del tarasco ${ }^{75} \mathrm{el} \mathrm{cual} \mathrm{ex-}$ plora a través de diferentes poemas incluidos en diversos libros sobre

el intercambio epistolar entre ambos contenido en la Special Collections de la Universidad de Chicago, cesa repentinamente. Paul Friedrich Papers, Special Collections, Universidad de Chicago, caja 5, folder 6 y caja 1, folder 16.

${ }^{69}$ Paul Friedrich, The Tarascan Suffixes of Locative Space: Meaning and Morphotactics, Language Research Monography núm. 9 (Bloomington: University of Indiana Press, 1971).

${ }^{70}$ Paul Friedrich, "Dialectical Variation in Tarascan Phonology", International Journal of American Linguistics 37(3) (julio de 1971): 164-187. También aparece en Paul Friedrich, Language, Context, and the Imagination, Ensayos (Stanford: Stanford University Press, 1979), 299-339.

${ }^{71}$ Paul Friedrich, "Metaphor-like Relations Between Referential Subsets", en Lingua (1) (1969): 1-10. También aparece en Paul Friedrich, Language, Context, and the Imagination, 391-401.

${ }^{72}$ Paul Friedrich, "Prolegomena to Tarascan", Paul Friedrich Papers, Special Collections, Universidad de Chicago, caja 4, folder 10, 1980, 53 páginas.

${ }^{73}$ Paul Friedrich, The Language Parallax, 61.

${ }^{74}$ Ibid., p. 47.

${ }^{75}$ Ibid., p. 3. 
etnopoesía. Su inspiración a menudo surge de su trabajo lingüístico: "¿Ves ese libro verde? [me dijo, refiriéndose a The Tarascan Suffixes...], es un tesoro. Es como una caja con cientos y cientos de palabras maravillosas [...] Me dije 'Voy a volver a él y ver qué significa poéticamente y empecé a escribir y escribir' [...] Hay un potencial poético enorme aquí aunque no parece poesía" ${ }^{76}$

En el poema II.a. de "El Tao del Lenguaje", Friedrich ejemplifica bellamente en veinte líneas la centralidad del cuerpo humano como prototipo de la geografía, como una red de significados entre la forma y el espacio dentro de la lengua tarasca.

\section{Poema II. a. ${ }^{77}$}

Dibujar rayas en la panza de una olla o rasparla por dentro, en su oquedad en su centro como el tallo de un nopal que se ha secado y retraído al interior de sus bordes o expandido como fruta que puede enmohecerse o podrirse como un abdomen que revienta de indigestión una matriz embarazada, inflamada, distendida sobada con las grises cenizas de un campo cubierto de maleza, pisoteado, en declive donde las gallinas son pelotas amontonadas esponjadas en su baño de polvo -los camposdonde montas y entras en un centro vientre con vientre, cara a cara o vives en el vagabundeo, pasas de un jardín a otro o vives arrejuntado y caminas por un campo y muchos campos más a solas hombre solitario u hombre sin mujeres y luego mueres, infante en una matriz o pequeña mazorca de maíz envuelta en sus hojas

${ }^{76}$ Entrevista de la autora a Paul Friedrich, Chicago, Il., 25 de mayo de 2014.

${ }^{77}$ Paul Friedrich, The Language Parallax, 74. 


\section{FRIEDRICH: HUMANISTA GLOBAL Y "WorLd ListeneR"}

Los intereses académicos de Paul Friedrich transitaron, como él, por el mundo. Como bien señaló Anwar S. Dil:

El trabajo de Paul ha mostrado luz sobre los valores humanos, las creencias, las ideas, actitudes y sentimientos que se expresan y simbolizan en diferentes lenguas y culturas. Tomado en conjunto, el trabajo de Paul muestra una visión individual única del mundo, inspirada en preocupaciones humanistas y científicas muy profundas. ${ }^{78}$

Para James Fernandez, Friedrich tuvo una vida de la más amplia "conectividad", que es el poder poético fundamental. ${ }^{79}$

Uno de los avances teóricos más importantes en la antropología reciente son las ideas de Friedrich sobre el caos, y el caos y el orden. Éstas se detallan en el último capítulo de The Language Parallax, donde desarrolla detalladamente una crítica a la obsesión lingüística y antropológica al concepto de orden y argumenta que el conocimiento constituye la imposición de cierto orden dentro del caos. ${ }^{80}$ Otra de sus contribuciones relevantes es su propuesta sobre la heteroglosia, es decir, la incorporación de una multiplicidad de voces surgidas/obtenidas a través del trabajo de campo, al resultado de la investigación para dar voz a los informantes; sin embargo, a diferencia de lo que propone una práctica científica más combativa, más comprometida y tan necesaria en el mundo, que dota de sentido social al conocimiento, Paul no sitúa a sus informantes tarascos en el nivel de coautores y, por otro lado, las voces que incorpora se limitan a los líderes varones de las comunidades estudiadas. El propio Friedrich reconoció que una de sus principales limitaciones fue el no poder dar voz a todos los sectores sociales que estudió ${ }^{81}$ (y, en última instancia, habría que considerar que éste es un pendiente en cada individuo, asunto al que ha

\footnotetext{
${ }^{78}$ Paul Friedrich, Language, Context, and the Imagination, xIV.

${ }^{79}$ James Fernandez, "Poetry, Power, and the Social Imagination".

${ }^{80}$ Paul Friedrich, The Language Parallax, capítulo viIr.

${ }^{81}$ Paul Friedrich, The Princes of Naranja, 89.
} 
dedicado muchas páginas: "La imaginación indeterminada del individuo es la 'realidad central del lenguaje". $)^{82}$

Una de las observaciones más interesantes que llevó a cabo Friedrich en Michoacán es la importancia de la autoadscripción indígena para definir quién lo es y quién no, en un momento cuando casi ningún estudioso en México lo había planteado y cuando aún en la actualidad hay serios debates en torno a este asunto:

Quizá el factor más importante en clasificar a un hombre como indio o no es si él se ve a sí mismo, y a su comunidad, como un indio aquí y ahora, y este factor nunca se ha tomado en cuenta adecuadamente [...] Para el propósito de mi tesis yo definiré al indio en términos de lengua, raza y conciencia de sí mismo. ${ }^{83}$

Aunque Tata Pablo manifiestó que "nunca he sido un relativista cultural en sentido simplista, ${ }^{84}$ se posicionaba al principio de sus obras a favor de la lucha del campesino tarasco por la tierra que trabaja, seńalando que los campesinos tienen derecho a la tierra, sobre todo, en los casos en que ésta les ha pertenecido tradicionalmente y que, en esas circunstancias, aprueba la expropiación y redistribución de la tierra. ${ }^{85}$ No titubeó para lanzar fuertes críticas al Instituto Nacional Indigenista y al gobierno mexicano con su mal orientada política indigenista al señalar que "éste ha sido culpable de un rápido y extremo empobrecimiento de la antiguamente 'rica cultura de México'"; 86 sin embargo, habría resultado muy enriquecedor escuchar en los textos de Friedrich la voz, los intereses y las necesidades de los informantes y de los demás habitantes de los pueblos donde trabajó, en ese afán que él señala repetidamente a lo largo de su obra global; estudiar al otro, para comprenderlo y respetarlo, pero tam-

${ }^{82}$ Stephen A. Tyler, "The Poetic Turn in Anthropology”, 332.

${ }^{83}$ Paul Friedrich Papers, Special Collections, Universidad de Chicago, caja 9, folder 13.

${ }^{84}$ Carta de Paul Friedrich a Nicholas ¿?, 8 de enero de 1964. Paul Friedrich Papers, Special Collections, Universidad de Chicago, caja 31.

${ }^{85}$ Paul Friedrich, Revuelta agraria en una aldea mexicana (México: Fondo de Cultura Económica, 1982), xVIII.

${ }^{86}$ Paul Friedrich Papers, Special Collections, Universidad de Chicago, caja 9, folder 17. 
bién para hacer conciencia de los problemas sociales que enfrentan millones de personas en el mundo.

Exigiendo de más a un intelectual de talla mundial, señalaría que una de las perspectivas que se extraña en el trabajo de Friedrich es el diálogo de saberes, el intercambio o la retribución en la práctica de los resultados de sus estudios con las sociedades y las personas que constituyeron sus objetos de análisis y sus fuentes de información. Mi impresión es que las obras del autor permanecen en el universo de la alta academia ${ }^{87}$ donde han tenido gran alcance e influencia entre especialistas y estudiosos de la historia política y social de México y América Latina, como John Womack, cuyo volumen sobre Zapata retoma el concepto de la política local formulado por Friedrich; Friedrich Katz, quien organizó un evento académico para discutir el tema de las revueltas locales a partir de los estudios de Paul Friedrich; o Jean Meyer, quien buscó entrevistarse con Friedrich para conocer detenidamente el método con el que desarrolló Revuelta agraria. La respuesta de Paul a Meyer fue escribir Los Príncipes de Naranja. ${ }^{88} \mathrm{Si}$ bien es cierto que la información manejada por Friedrich fue altamente sensible y llevó implícito un riesgo a la integridad física de los informantes y del propio antropólogo, quien temía las consecuencias de hacer pública su investigación y llegó a anotar en varios documentos personales que "debido al carácter extremadamente íntimo y personal de la información, deseo que este trabajo nunca se publique en espańol, ni aun con los nombres cambiados", ${ }^{89}$ también hay que decir que los trabajos fueron publicados en las décadas subsecuentes cuando la mayoría de los personajes involucrados ya habían fallecido. La tesis original "Cacique: The Recent Political History of a Tarascan Village", compuesta por dos

${ }^{87}$ En los más de 15 años que he sido profesora de pre y posgrado en una universidad pública mexicana de provincia he notado que casi ninguno de mis estudiantes conocía los textos de Friedrich antes de leerlos en mis clases. Ésta fue una de las principales razones que me motivaron a escribir este texto.

${ }^{88}$ Entrevista de la autora a Paul Friedrich, Chicago, Il., 25 de mayo de 2014.

${ }^{89}$ Paul Friedrich Papers, Special Collections, Universidad de Chicago, caja 11, folder 2 . 
volúmenes, continúa con el estatus "On Reserve" indefinido en la Universidad de Yale. ${ }^{90}$

Friedrich fue pionero en otro aspecto muy poco trabajado en aquel tiempo: los estudios sobre la feminidad a través de sus análisis de los mitos griegos y de la sensualidad/sexualidad simbolizada en Afrodita. En su obra The Meaning of Aphrodite, Paul reconstruye el significado de la feminidad postulando la idea de que esta diosa representaba las concepciones de la maternidad y la sexualidad amalgamadas, es decir, trataba de hacer visibles las similitudes entre el amor materno y el amor erótico, este planteamiento le generó críticas y antipatías, pero que hoy se ha tornado muy relevante. En su obra sobre los indígenas michoacanos se ańora esa perspectiva sobre la feminidad que él mismo desarrolló en otros trabajos; por supuesto, aborda la importancia de los vínculos matrilineales o de algunas mujeres cercanas a los líderes, pero desde una visión tangencial a partir de los caciques/príncipes. En sus fascinantes poemas sobre motivos tarascos, por el contrario, canta la belleza y la sensualidad femenina, el despertar de la sexualidad y la maravilla de la maternidad, permitiendo al lector adentrarse y transmutarse por instantes en el mundo de la mujer tarasca.

Tata Pablo siguió yendo cotidianamente a Foster Hall 305 -su oficina en la Universidad de Chicago-, publicó activamente y regresó a disfrutar de su "primer amor": la lengua y la literatura rusas en los últimos años de su vida. Falleció el 11 de agosto de 2016 en su casa de Hyde Park en Chicago a los 89 años de edad.

${ }^{90}$ Paul Friedrich, "Cacique: The Recent Political History of a Tarascan Village" (Tesis doctoral en Etnología. Director Sidney Mintz, Yale University, 1957) es producto de la primera temporada de investigación de Friedrich en Michoacán (1955-1957). Fue puesta "bajo reserva" en la Universidad de Yale ya que en ella se manejan los nombres auténticos de los príncipes y caciques de Naranja. Los textos publicados a partir de esta misma investigación manejan seudónimos. A la fecha, no es posible consultar la tesis. Tuve acceso a la misma gracias a los dos volúmenes originales que conservaba el profesor Friedrich y que amablemente me permitió consultar. 


\section{Documentos De ARCHIVO}

Colección “Paul Friedrich Papers", Special Collections, Universidad de Chicago. 49 cajas.

Bibliografía selecta de Paul Friedrich (InCluye textos SOBRE MiCHOACÁN Y OTROS QUE HAN SIDO RECONOCIDOS INTERNACIONALMENTE)

Friedrich, Paul. "Cacique: The Recent Political History of a Tarascan Village”. Tesis Doctoral en Etnología. Director Sidney Mintz. Yale University, 1957 (Tesis reservada indefinidamente).

. "A Tarascan Cacicazgo: Structure and Function". En Systems of Political Control and Bureaucracy in Human Societies, ed. Verne F. Ray, Proceedings of the 1958 Annual Spring Meeting of the American Ethnological Society. Seattle: 1958.

. "Assumptions Underlying Tarascan Political Homicide". Psychiatry: Journal for the Study of Interpersonal Processes 25(4) (noviembre de 1962): 315-327. 190-209.

. "El parentesco y la política en una aldea mexicana”. En $M e-$ morias del XXXVI Congreso Internacional de Americanistas. Sevilla: 1966.

. "Revolutionary Politics and Communal Ritual". En Political Anthropology, ed. Marc J. Swartz, Victor W. Turner y Arthur Tuden, 191-220. Chicago: Aldine Publishing Company, 1966.

. "Metaphor-like Relations Between Referential Subsets". Lingua (1) (1969): 1-10; y en Paul Friedrich. Language, Context, and the Imagination, 391-401.

. Agrarian Revolt in a Mexican Village. Chicago: PrenticeHall, University of Chicago Press, 1970. Traducido al español como Paul Friedrich, Revuelta agraria en una aldea mexicana. México: Fondo de Cultura Económica, 1982.

. The Tarascan Suffixes of Locative Space: Meaning and Mor- 
photactics. Language Research Monography núm. 9. Bloomington: University of Indiana Press, 1971.

. "Dialectical Variation in Tarascan Phonology". International Journal of American Linguistics 37(3) (julio de 1971): 164-187; y en Paul Friedrich, Language, Context, and the Imagination, 299-339.

. "Shape Categories in Grammar". Linguistics: An International Review (77) (1972): 5-22; y en Paul Friedrich. Language, Context, and the Imagination, 340-359.

A Phonology of Tarascan. Chicago: University of Chicago Press, 1973.

. The Meaning of Aphrodite. Chicago: University of Chicago Press, 1978.

. Language, Context, and the Imagination. Ensayos. Stanford: Stanford University Press, 1979, 299-339.

. "Prolegomena to Tarascan". Paul Friedrich Papers. Special Collections. Universidad de Chicago, caja 4, folder 10, 1980, 53 páginas.

. The Language Parallax. Linguistic Relativism and Poetic Indeterminacy. Austin: University of Texas Press, 1986.

. "The Master Trope. The Poetic Polarity: Music", Dialectical Anthropology (11) (1986): 325-328.

"Multiplicity and Pluralism in Anthropological Construction/Synthesis", Anthropological Quaterly 61(3) (1988): 103-112. . The Princes of Naranja. An Essay in Anthrohistorical Method. Austin: University of Texas Press, 1987. Traducido al español como Los Príncipes de Naranja. Un ensayo de método antropohistórico. México: Grijalbo, 1991.

"El Tao del Lenguaje". En Fundamentos de Antropología. Granada: Diputación Provincial de Granada, Centro de Investigaciones Etnológicas Ángel Ganivet, 1994, 64-81. . Music in Russia Poetry. Nueva York: Peter Lang, 1998. "Return to Yale or Toward an Essay on Analogy", charla presentada en la Universidad de Yale, 2007. Texto inédito facilitado por el profesor Friedrich a la autora.

. The Gita within Walden. Albany: SUNY Press, 2008. 
. The Goldfinch Instant, Concord to India Haikus. VAC Press, 2010.

. "Two long walks and two short nights". En Writing in the Field. Festschrift for Stephen Tyler, ed. Strecker Ivo y Shauna LaTosky, 3-5. Berlín: Lit Verlag, 2013.

Friedrich, Paul y Dale Pesmen. "A Conversation with Paul Friedrich”. Annual Review of Anthropology, vol. 43 (2014): 15-26.

Friedrich, Paul y John AtTinasi. "Dialogic Breakthrough: Catalysis and Synthesis in Life-Changing-Dialogue". En The Dialogic Emergence of Culture, ed. Dennis Tedlock y Bruce Mannheim, 33-53. Chicago: University of Illinois, 1995.

Friedrich, Paul y K. N. Parameshwaran Nayar, editores y traductores de Tagari Shivashankara Pillai. "Under the Mango Tree". Texas Quarterly 7(2): 54-63.

\section{REFERENCIAS}

Brady, Ivan, ed. Anthropological Poetics. Nueva York: Rowman and Littlefield Publishers, 1991.

Cuifford, James y George E. Marcus. Writing Culture, The Poetics and Politics of Ethnography. Berkeley: University of California Press, 2010.

Cor, Peter. Reseña de Paul Friedrich, The Princes of Naranja: An Essay in Anthrohistorical Method. Austin: University of Texas Press, 1986. Journal of Latin American Studies 20(1) (1988): 220-222.

Evans-Pritchard, Edward, ed. Peoples of the Earth. Vol. 4, ed. Julian Pitt-Rivers. Londres: Danbury Press, 1973.

Fabian, Johannes. "The Other and Anthropological Writing". Critical Inquiry 16(4) (verano de 1990): 753-772.

Fernandez, James. "Poetry, Power, and the Social Imagination", ponencia en el simposio sobre la obra de Paul Friedrich y su influencia, 112a Reunión Anual de la American Anthropological Association, Chicago, 2013 (Texto proporcionado por el autor).

Friedrich, Lenore Pelham. "I had a baby". Atlantic Montly (abril de 1939): 461-465.

Mascia-Lees, Frances, Patricia Sharpe y Colleen Ballerino Co- 
HEN. "The Postmodernist Turn in Anthropology: Cautions from a Feminist Perspective”. Signs 15(1): 7-33.

Rabinow, Paul. Reflections on Fieldwork in Morocco. Berkeley y Los Ángeles: University of California Press, 1977.

RedFIELD, James. "Paul Friedrich: Ethnographer as Poet and Poet as Ethnographer". Dialectical Anthropology 11(2-4): 351-353.

Rosaldo, Renato. Culture and Truth. The Remaking of Social Analysis. Boston: Beacon Press, 1993.

Tyler, Stephen A. "The Poetic Turn in Anthropology: The Poetry of Paul Friedrich". American Anthropologist 86(2) (junio de 1984): 332 . 